\title{
Multiple sclerosis in Canada 2011 to 2031: results of a microsimulation modelling study of epidemiological and economic impacts
}

\author{
Nana Amankwah, MSc (1); Ruth Ann Marrie, MD, PhD (2); Christina Bancej, PhD (1); Rochelle Garner, PhD (3); \\ Douglas G. Manuel, MD (3,4,5,6,7,8,9); Ron Wall, PhD (1); Philippe Finès, PhD (3); Julie Bernier, MA (3); \\ Karen Tu, MD (9,10,11); Kim Reimer, BSc (12)
}

This article has been peer reviewed.

Tweet this article

\begin{abstract}
Introduction: The objective of our study was to present model-based estimates and projections on current and future health and economic impacts of multiple sclerosis (MS) in Canada over a 20-year time horizon (2011-2031).

Methods: Using Statistics Canada's Population Health Microsimulation Model (POHEM) framework, specifically the population-based longitudinal, microsimulation model named POHEM-Neurological, we identified people with MS from health administrative data sources and derived incidence and mortality rate parameters from a British Columbia population-based cohort for future MS incidence and mortality projections. We also included a utility-based measure (Health Utilities Index Mark 3) reflecting states of functional health to allow projections of health-related quality of life. Finally, we estimated caregiving parameters and health care costs from Canadian national surveys and health administrative data and included them as model parameters to assess the health and economic impact of the neurological conditions.
\end{abstract}

Results: The number of incident MS cases is expected to rise slightly from 4051 cases in 2011 to 4794 cases per 100000 population in 2031, and the number of Canadians affected by MS will increase from 98385 in 2011 to 133635 in 2031. The total per capita health care cost (excluding out-of-pocket expenses) for adults aged 20 and older in 2011 was about \$16 800 for individuals with MS, and approximately $\$ 2500$ for individuals without a neurological condition. Thus, after accounting for additional expenditures due to MS (excluding out-of-pocket expenses), total annual health sector costs for MS are expected to reach $\$ 2.0$ billion by 2031. As well, the average out-of-pocket expenditure for people with MS was around $\$ 1300$ annually throughout the projection period.

Conclusion: MS is associated with a significant economic burden on society, since it usually affects young adults during prime career- and family-building years. Canada has a particularly high prevalence of MS, so research such as the present study is essential to provide a better understanding of the current and future negative impacts of MS on the Canadian population, so that health care system policymakers can best plan how to meet the needs of patients who are affected by MS. These findings also suggest that identifying strategies to prevent MS and more effectively treat the disease are needed to mitigate these future impacts.

\section{Highlights}

- Multiple sclerosis (MS) is associated with a significant economic burden on society.

- The number of incident MS cases is expected to rise slightly in Canada from 4051 cases in 2011 to 4794 cases per 100000 population in 2031.

- The MS prevalence for women aged 20 years and older is approximately 3 times higher than that for men.

- Most people affected by MS have an informal caregiver.

- Direct costs and indirect costs (e.g. out-of-pocket expenses) associated with MS are expected to increase over the next 20 years.

Keywords: multiple sclerosis, economic burden, Canada, microsimulation modelling, incidence, prevalence

\section{Introduction}

Multiple sclerosis (MS) is an unpredictable, chronic, inflammatory and degenerative disease of the central nervous system. ${ }^{1-4}$ It is the most common non-traumatic disabling neurological condition among young

Author references:

1. Public Health Agency of Canada, Ottawa, Ontario, Canada

2. Department of Internal Medicine (Neurology) and Department of Community Health Sciences, University of Manitoba, Winnipeg, Manitoba, Canada

3. Health Analysis Division, Statistics Canada, Ottawa, Ontario, Canada

4. Ottawa Hospital Research Institute, Ottawa, Ontario, Canada

5. University of Ottawa, Ottawa, Ontario, Canada

6. Bruyère Research Institute, Ottawa, Ontario, Canada

7. School of Public and Population Health, University of Ottawa, Ottawa, Ontario, Canada

8. Institute for Clinical Evaluative Sciences, Ottawa, Ontario, Canada

9. Institute for Clinical Evaluative Sciences, Toronto, Ontario, Canada

10. Department of Family and Community Medicine, Department of Medicine and Institute of Health Policy, Management and Evaluation, University of Toronto, Toronto, Ontario, Canada

11. Toronto Western Hospital Family Health Team, University Health Network, Toronto, Ontario, Canada

12. Population Health Surveillance and Clinical Prevention, British Columbia Ministry of Health, Victoria, British Columbia, Canada

Correspondence: Nana Amankwah, Social Determinants and Science Integration Directorate, Health Promotion and Chronic Disease Prevention Branch, Public Health Agency of Canada, Room 903 A3, 785 Carling Avenue, Ottawa, ON K1A 0K9; Tel: 613-291-3181; Email: nana.amankwah@phac-aspc.gc.ca 
adults in Canada. ${ }^{5}$ Onset is typically between the ages of 20 and 40 years, and women are affected more often than men., Although the etiology of MS remains unknown, genetic predisposition and environmental factors jointly trigger the disease. $^{2,6}$

The prevalence of MS varies geographically, and high-prevalence areas include Canada, the northern United States, most of northern Europe, New Zealand, southeastern Australia and Israel. ${ }^{7}$ The prevalence of MS in Canada is among the highest worldwide. ${ }^{8}$ Because onset of MS occurs at a relatively early age, it affects individuals during their most productive years, and they face challenges in the workforce including underemployment, unemployment and long-term disability. ${ }^{9-12}$ According to the MS Society of Canada's Action on MS report, ${ }^{13}$ nearly $80 \%$ of Canadians with MS may find themselves unemployed. Determining the reasons for the high prevalence and lessening the burden of living with MS and other chronic neurological conditions have become major health policy concerns in Canada. Therefore, the Government of Canada initiated the National Population Health Study of Neurological Conditions (NPHSNC) to increase understanding of these conditions, with the long-term goal of reducing the burden of neurological conditions in Canada. ${ }^{9}$

Given the societal effects of MS, it is essential that comprehensive studies are undertaken to deal with the current impact and to plan for the future impact of the disease. We used Statistics Canada's Population Health Microsimulation Model (POHEM) framework, specifically the population-based, longitudinal, microsimulation model named POHEM-Neurological, to examine the health and economic impacts of the disease in Canada, including the expected incidence, prevalence, mortality and direct and indirect costs associated with MS over a 20-year time horizon from 2011 to 2031. The objective of this study is to provide key information to help shape strategies and public health policies on MS.

\section{Methods}

\section{Population Health Model (POHEM)-Neurological}

Statistics Canada's POHEM-Neurological framework is a population-based, longitudinal, microsimulation model ${ }^{14}$ created as part of Canada's NPHSNC. The NPHSNC included 13 research projects and three national surveys aimed at examining multiple neurological conditions affecting Canadians. ${ }^{9,14,15}$ The POHEM model was generated using MODGEN (Model Generator) software, version 11, a microsimulation programming language developed by Statistics Canada. ${ }^{14}$ The model was developed to project the burden of select neurological conditions in Canada, including MS, from a societal perspective that includes health impacts and direct and indirect heath care costs by synthesizing the wide range of information from projects within the NPHSNC. POHEM is an empirically grounded model that uses Canadian demographic data and estimates of disease incidence and mortality rates to produce projections over the life cycle dynamics of Canadians. ${ }^{16}$ The model's basic unit of analysis is individual people, or "actors," whose life course is modelled in continuous time using a Monte Carlo* approach. The dynamic simulation recreates the Canadian population at a given point in time (historically and in the future) and ages it, one actor at a time, until each actor's death.

\section{Model characteristics}

Caregivers, clinicians and individuals with policy expertise provided advisory input to the POHEM-Neurological model. ${ }^{14}$ The project's advisors and research team created the model specification, including the purpose, structure and data sources. The main characteristics of the model were as follows:

- Population-based-reflecting the Canadian population, including important subpopulations designated by age, sex and region.

- Open with respect to populationallowing the population to change over time to reflect historical and projected births, deaths, immigration and emigration.
- Coherent and consistent-using a common definition of MS throughout the model and consistent in the approach used to model the epidemiology and costs related to the condition. Case ascertainment required that a clinician diagnose MS. A generic preferencebased measure of health-related quality of life, the Health Utilities Index Mark 3 (HUI3; described later), was used to ascertain disease severity. ${ }^{17}$

- High predictive accuracy-able to generate accurate projections for the total Canadian population and for specific sex and age subgroups.

- Useful for population health planning-can be used to estimate future MS burden, including health care costs and caregiver burden.

- Flexible and robust-able to be developed further. Risk factors for the development of MS apart from age and sex were excluded from the current study. However, sociodemographic and health behaviour risk factors are part of other POHEM disease models and NPHSNC studies, and risk factors could be included in future MS modelling. ${ }^{18}$

\section{Model development}

Four steps made up the process of microsimulation model development: initialization, yearly updates, model validation and projection (Table 1). Only Canadian, population-based data sources were used for model initialization and yearly updates (data not shown; available from the authors upon request).

\section{Initialization}

Initialization began with historic birth cohorts from 1872, which we subjected to the observed historic death rate, similar to other Statistics Canada health models. ${ }^{19,20}$ We added migration (immigration and emigration) to the birth cohorts, also reflecting historic observed or estimated events. The birth cohorts used observed data up to 2006; and projected births, deaths and migration following standard Canadian population projections (midgrowth scenario) as estimated by Statistics Canada for 2007 onward.

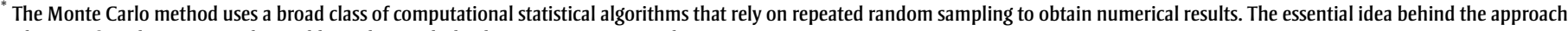
is the use of randomness to solve problems that might be deterministic in principle.
} 
TABLE 1

Process for projecting multiple sclerosis prevalence, health burden and health care use in Canada using the POHEM-Neurological

\begin{tabular}{|c|c|c|}
\hline Model generating step & Model activity & Details of the model step \\
\hline $\begin{array}{l}\text { Step 1: } \\
\text { Generate an initial Canadian } \\
\text { population }\end{array}$ & $\begin{array}{l}\text { Initiated a predictive model by creating a synthetic } \\
\text { cohort of Canadians. }\end{array}$ & $\begin{array}{l}\text { Historic birth cohorts combined with annual deaths, immigration, and } \\
\text { emigration. Observed demographic data to } 2006 \text { projected to 2031. }\end{array}$ \\
\hline $\begin{array}{l}\text { Step 2: } \\
\text { Update annual MS incidence } \\
\text { and other model parameters }\end{array}$ & $\begin{array}{l}\text { Each year to 2031, update population characteristics, } \\
\text { MS incidence, health status and health care costs. }\end{array}$ & $\begin{array}{l}\text { Each year, update synthetic cohort for demographic changes, MS } \\
\text { incidence and deaths. For people with and without MS, estimate Health } \\
\text { Utilities Index, health care use (formal and informal) and deaths. }\end{array}$ \\
\hline $\begin{array}{l}\text { Step 3: } \\
\text { Validate and calibrate the model }\end{array}$ & $\begin{array}{l}\text { Compare projected MS to observed prevalence in } \\
2009 .\end{array}$ & $\begin{array}{l}\text { Compare projected to observed MS prevalence, by age and sex. } \\
\text { Calibrate the model if needed (no calibration undertaken for MS). }\end{array}$ \\
\hline $\begin{array}{l}\text { Step 4: } \\
\text { Generate final projections from } \\
\text { 2011-2031 }\end{array}$ & $\begin{array}{l}\text { Project MS incidence, prevalence, mortality, health } \\
\text { utilities index and health care costs from 2011- } \\
2031 .\end{array}$ & Generate output tables from projections. \\
\hline
\end{tabular}

Abbreviations: MS, multiple sclerosis; POHEM, Population Health Model.

${ }^{\text {a }}$ See text for MS incidence, initialization, progression and mortality.

\section{Yearly updates of actors' health profiles}

An actor's health profile consists of six characteristics: (1) demographics (e.g. age, province of residence); (2) MS status; (3) health status; (4) presence of an informal caregiver; (5) health care costs; and (6) mortality (date of death). Each actor's health profile was updated throughout the year, either at the occurrence of an event (e.g. birthday, date of diagnosis of MS) or at the change of the calendar year, depending on the profile characteristic. All characteristics were calculated and modelled for people with and without $\mathrm{MS}^{20}$ (data sources available from authors upon request).

\section{Model implementation}

Figure 1 shows life-course parameters used in the simulation model.

\section{MS status: incidence}

Since the model uses status quo assumptions to project the future impact, it assumes that MS incidence and risk and prognostic factors will remain stable throughout the projection period, consistent with findings in Nova Scotia ${ }^{21}$ and Manitoba. ${ }^{22}$ We generated prevalent MS actors in two steps. First, we applied empirical estimates of sex- and age-specific MS incidence rates to the model's synthetic Canadian population for each year, both historical and projected. We estimated incidence rates using a validated case definition algorithm ${ }^{\dagger}$ that had a sensitivity of $84.0 \%$ for adults aged 20 years and older, ${ }^{23}$ and specificity of $99.9 \%{ }^{24}$ applied to a cohort from the province of Ontario. Individuals under age 20 years were excluded, given the low incidence of acquired demyelinating syndromes (ADS) leading to MS in Canadian children and adolescents. Incidence and prevalence rates estimated from the British Columbia (BC) population were of comparable magnitude to those of the published studies from Canadian settings and provincial/territorial pilots. ${ }^{22-25}$

Using these age- and sex-specific incidence rates, actors were classified as being diagnosed with MS, based on each actor's risk of developing MS at the beginning of each new calendar year. Incident MS cases accumulated over time to generate prevalent cases of MS.

Second, we applied MS-specific mortality risk to actors with MS. The MS mortality risk was a product of a mortality ratio for people with MS multiplied by the baseline mortality rate for the Canadian population within POHEM-Neurological. The general population mortality rate gradually decreases over time, reflecting the projected mortality (life expectancy) using birth cohorts and the Lee-Carter model as estimated by Statistics Canada. ${ }^{26}$ This means that the projected mortality for people with MS decreased at the same rate as for Canadians living without MS, largely consistent with observations in British Columbia. ${ }^{27}$ Using the $\mathrm{BC}$ administrative data prevalence cohort, we examined the number of deaths among individuals with MS, and compared it to the death rate among individuals without a neurological condition.

\section{Health status}

HUI3 is a utility-based measure that reflects health states ranging from perfect health (HUI3 $=1.0$ ) through death (HUI3 = 0), including states considered to be worse than death (minimum HUI3 $=-0.36$ ), allowing for a range of severity levels. ${ }^{17}$ The HUI3 assesses functional health across eight dimensions-cognition, emotion, mobility, dexterity, pain and discomfort, speech, vision and hearing - and was used based on the need for a common framework to assess functional health and disability due to MS. It validly measures and predicts functional health status and quality of life in people with MS. ${ }^{17,28,29}$ Age-specific HUI3 means for people with MS were estimated from the 2011 Survey on Living with Neurological Conditions in Canada (SLNCC), ${ }^{30}$ while HUI3 values for people without MS were derived from all cycles (1994-2010) of the National Population Health Survey (NPHS). ${ }^{31}$

The impact of MS can also be assessed by the years of life lost (YLL) due to the condition, that is, years lost due to premature death from a disease. To perform the YLL calculation, we first calculated the age of death for all actors with MS in each calendar year. Next, we estimated YLL for a scenario in which the mortality hazard for MS was the same as for actors without MS and recalculated the age of death: YLL was the

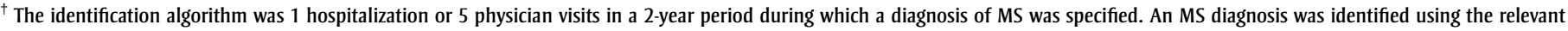
International Classification of Disease (ICD) codes: (1) ICD-9(CM) 340; or (2) ICD-10(CA) G35.
} 
FIGURE 1

Overview of the POHEM-Neurological model implementation

\section{SIMULATION MODEL}

\begin{tabular}{|c|c|c|c|}
\hline Birth/POP & Incidence & Progression & Death \\
\hline \multicolumn{4}{|c|}{ Input parameters } \\
\hline Birth/POP & Incidence rates & Progression & Mortality \\
\hline $\begin{array}{l}\text { - Births, deaths, } \\
\text { migration from } \\
\text { 1872-2051 }\end{array}$ & $\begin{array}{l}\text { Disease } \\
\text { incidence } \\
2006-2010 \text { by } \\
\text { sex and age } \\
\text { groups } \\
(<1,1-4, \ldots, \\
80-84,85 \\
\text { years and } \\
\text { older) }\end{array}$ & $\begin{array}{l}\text { - Based on } \\
\text { literature/ } \\
\text { expert opinion } \\
\text { - Calculate rate } \\
\text { to approximate } \\
\text { Canadian } \\
\text { prevalence as } \\
\text { benchmark }\end{array}$ & $\begin{array}{l}\text { - Relative } \\
\text { mortality of } \\
\text { people with } \\
\text { condition vs. } \\
\text { overall } \\
\text { population, by } \\
\text { age and sex } \\
\text { (2006-2010) }\end{array}$ \\
\hline
\end{tabular}

Functional health (HUI3), health sector costs, presence of caregiver, hours of informal care, out-of-pocket costs

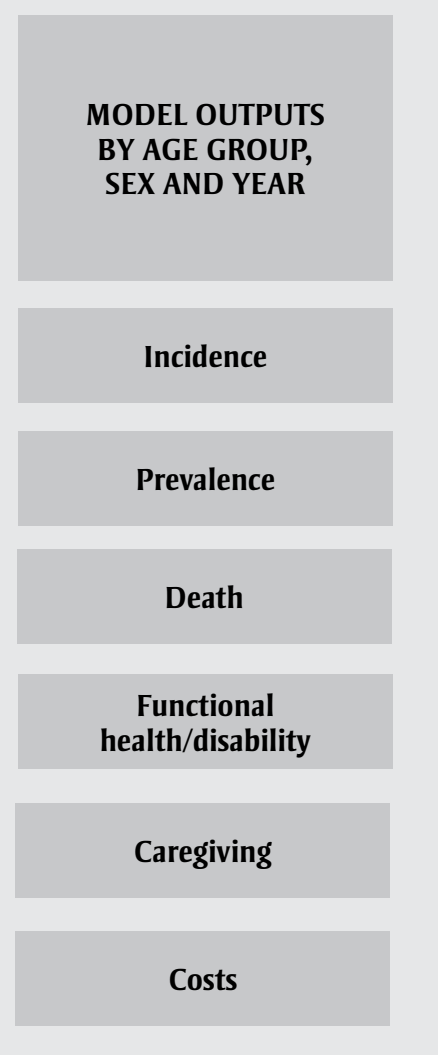

Abbreviations: HUI3, Health Utilities Index Mark 3; POHEM, Population Health Model; POP, population.

difference in age of death between the two calculations. Health-adjusted life years lost (HYLL) indicates the years of life lost living in a healthy state, combining morbidity and mortality experience, and was estimated from the product of years of life lived (age of death) multiplied by the annual HUI3 for each actor over their lifetime.

\section{Informal caregiving}

Informal caregiving refers to unpaid caregiving provided by family and friends to Canadians living with a chronic health condition, disability or aging needs. For each actor in the model, we assessed informal caregiving at the end of every calendar year based on an actor's age, MS status and health status (HUI3). If an individual was assigned the presence of an informal caregiver, additional characteristics were also assigned based on empirical estimates from SLNCC and augmented with the 2012 General Social Survey (GSS) ${ }^{32}$ : (1) hours of care received; (2) health status of their caregiver; and (3) out-of-pocket expenses incurred by caregivers.

\section{Health care costs}

Formal health care costs were estimated among incident and prevalent cohorts with MS, and were ascertained using administrative data in British Columbia and Ontario. We estimated the health care costs using 2010-dollar value; as such, inflation is not factored into the costs projections. In addition, prevalent and counterfactual cohort costs were obtained for the period 01 April, 2009, through 31 March,
2010, in both Ontario and BC. We examined incident cohort costs in Ontario over the same period. We obtained available incident cohort costs in BC for the 12-month period starting on 01 April of the incident year $(2006,2007$ or 2008).

Formal health care costs were those covered by provincial health plans in health components grouped as follows: (1) acute hospitalization; (2) physician services; (3) prescription drugs data; ${ }^{\ddagger}$ (4) rehabilitation hospitals; (5) Ontario provincially funded home care; (6) Ontario residence and care in a long-term care facility; and (7) Ontario provincially funded assistive devices. Also, per capita out-of-pocket caregiver costs and informal care by caregivers (hours of care per week) were

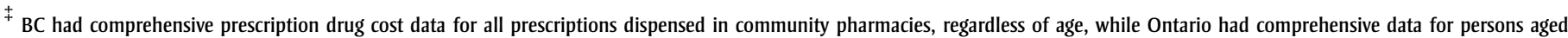

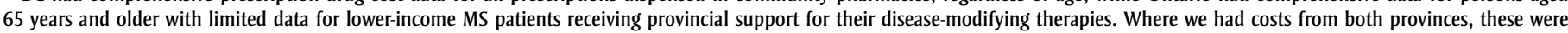

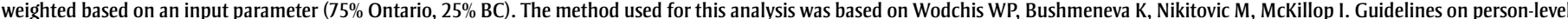

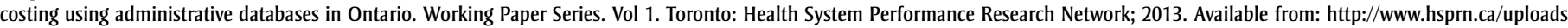
/files/Guidelines_on_PersonLevel_Costing_May_2013.pdf
} 
estimated from a national sample of caregivers from the 2012 GSS, whereas per capita out-of-pocket costs to individuals living with neurological conditions were estimated from a national sample through the SLNCC. Out-of-pocket expenses were those expenses not covered by private insurance or provincial health care plans, such as the cost of prescription and overthe-counter medications, assistive devices, rehabilitation therapy such as physical or occupational therapy and home care services. We estimated formal health costs separately for incident cases (within the first 12 months following incidence) or prevalent case (one year or more since incidence) of MS. As out-of-pocket costs are not captured in administrative databases, we used survey data to assess those expenses.

Comorbidity, counterfactual population and costs estimation

Individuals living with MS frequently have comorbid conditions. ${ }^{33,34}$ Such conditions may be precursors to or related sequelae of MS, or may be present independent of MS. Individuals both with and without MS may experience some of these conditions. As such, it is sometimes difficult to isolate the contribution of MS to health care costs, caregiving or mortality, in the presence of comorbid conditions. To address this issue, we identified a counterfactual (nonneurological) population cohort to determine the net impact of MS. For example, if the prevalence of comorbidity $\mathrm{X}$ is greater among individuals with MS than without MS, then the additional health care costs (or receipt of caregiving hours) associated with this greater morbidity should be attributed to individuals living with MS. Conversely, if individuals with MS use less of a particular health care resource compared to individuals without a neurological condition, this lower utilization should also be reflected in our model.

The counterfactual nonneurological cohort consisted of all individuals in the respective datasets who had not otherwise been classified as having any of the seven neurological conditions of interest for the NPHSNC microsimulation project. In addition to MS, these conditions were Alzheimer's disease and other dementias, cerebral palsy, epilepsy, Parkinson's disease and parkinsonism, traumatic brain injuries and traumatic spinal cord injuries.

\section{POHEM-Neurological validation}

The model-projected prevalence of MS in 2010 was higher than that observed in the British Columbia data, and higher than that reported in some, but not all, Canadian provinces. Prevalence estimates across Canada are variable, with estimates per 100000 population based on administrative data ranging from 207.3 in Ontario in $2010^{24}$ to 266.9 in Nova Scotia in $2010,{ }^{21}$ and as high as 357.6 in the contiguous province of Alberta in 2004. ${ }^{35}$ Despite this variance, the estimated age- and sex-specific prevalence rates are quite similar to estimates based on the 2010-11 ${ }^{36}$ Canadian Community Health Survey (CCHS; see Figure 2), recognizing that the CCHS did not capture those living in long-term care, who represent $5.8 \%$ to $9.2 \%$ of the MS population aged 65 years and older. ${ }^{37}$ As such, we made no additional calibration to adjust POHEM-Neurological MS prevalence projections.

\section{Projection}

We projected 13 main model outputs through to 2031 including: (1) incident and prevalent

FIGURE 2

Prevalence rates of multiple sclerosis, by age and sex, projected from the POHEM-Neurological and estimates from other data sources, Canada, various dates

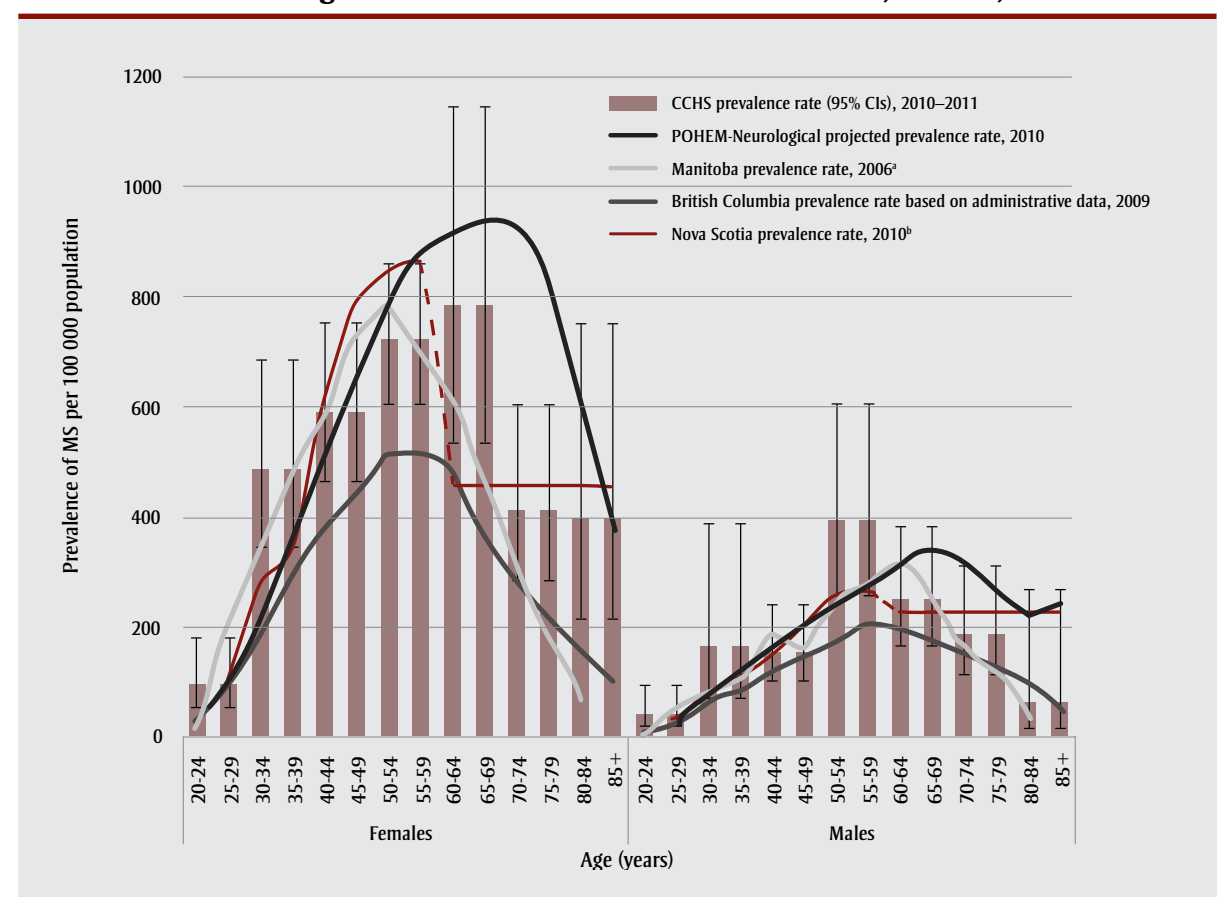

Abbreviations: CCHS, Canadian Community Health Survey; Cl, confidence interval; MS, multiple sclerosis; POHEM, Population Health Model.

${ }^{a}$ From Marrie et al., 2010.22

${ }^{b}$ From Marrie et al., 2013. ${ }^{21}$
MS cases in Canada; (2) YLL with MS; (3) HYLL; (4) health care costs, including costs for each of the seven sectors; (5) outof-pocket expenses; and (6) hours of informal caregiving. In addition, we projected three parameters from the perspective of caregivers for MS: (1) hours of caregiving; (2) out-of-pocket expenses; and (3) health status (HUI3).

\section{Results}

The number of incident MS cases is expected to rise slightly from 4051 cases in 2011 to 4794 cases per 100000 population in 2031 (data not shown). Among Canadians aged 20 years and older, MS prevalence is projected to rise gradually from 380 per 100000 population in 2011 to 430 per 100000 population in 2031, corresponding to 98835 Canadians living with MS in 2011 and 133635 Canadians living with MS in 2031 (Figure 3). The small increase in prevalence over the 20-year horizon reflects the assumption of stable MS incidence and mortality.

The MS prevalence for women aged 20 years and older is approximately 3 times higher than that for men (Figure 4). In 
FIGURE 3

POHEM-Neurological projected multiple sclerosis prevalence count (person years) and rate, population aged 20 years and older, both sexes, Canada, 2011-2031

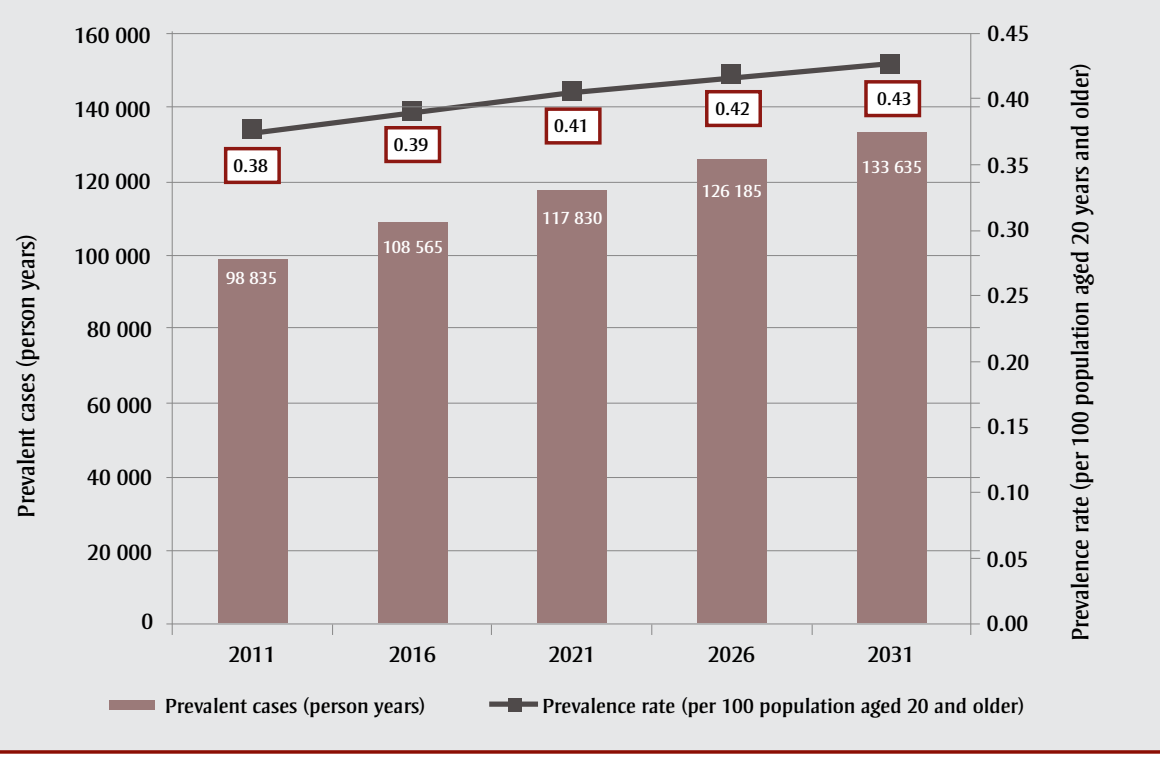

Abbreviation: POHEM, Population Health Model.
2011, the prevalence per 100000 population was 580 for women compared to 200 for men. In 2031, the model projected a rate of 620 per 100000 population for women compared to 220 per 100000 for men. The prevalence of MS increases dramatically for both sexes from ages 20 to 24 years until the age group 60 to 69 , after which the prevalence begins to decline, reflecting the fact that incidence is highest for individuals in their late thirties through their early sixties.
FIGURE 4

POHEM-Neurological projected multiple sclerosis prevalence count (person years) and rate, by age and sex, Canada, 2011 and 2031

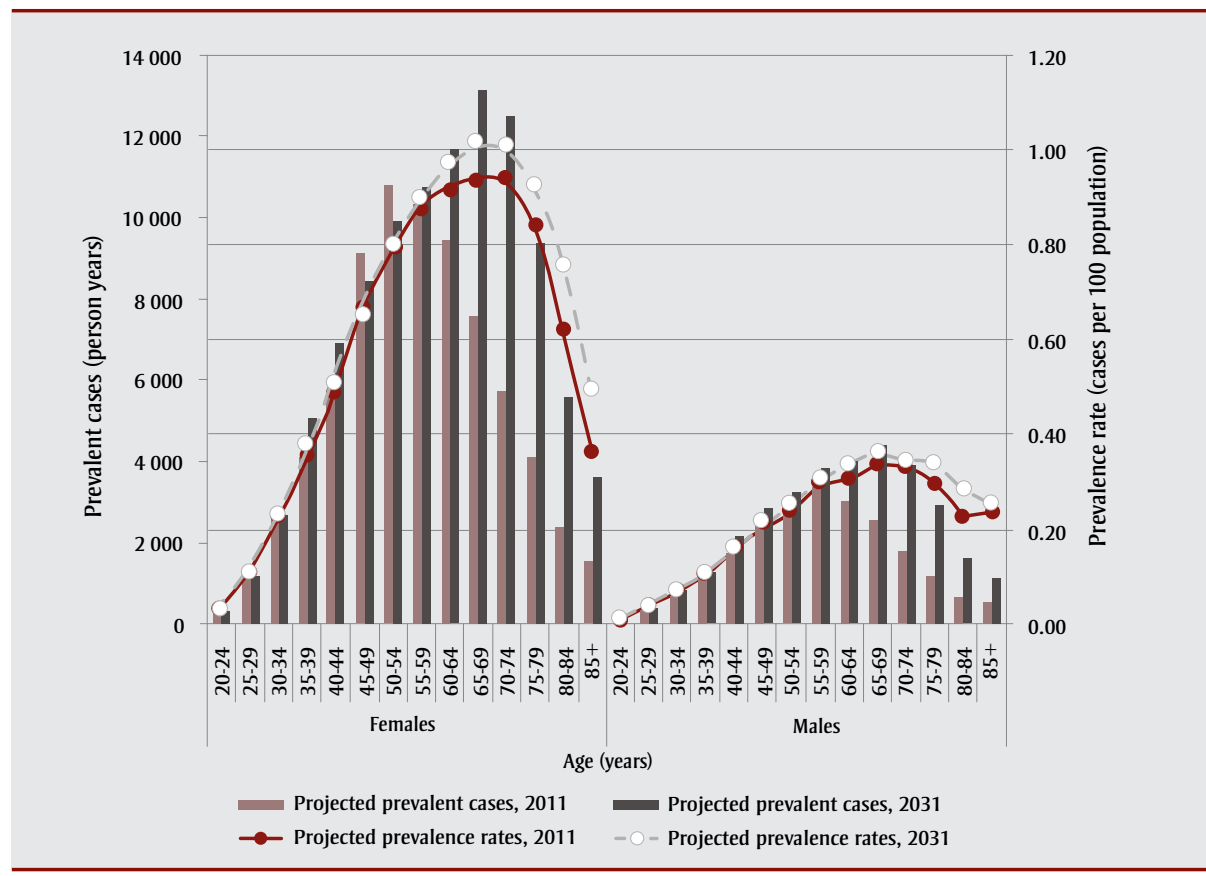

Abbreviation: POHEM, Population Health Model.
Regarding functional health and disability due to MS, the SLNCC showed that people of both sexes with MS have lower HUI3 scores compared to people with no neurological condition (Figure 5). Although HUI3 scores declined with age in both populations, on average, the HUI3 declined 15 years earlier in the MS population, and the gap in HUI3 scores persisted across all age groups. These trends were projected to remain the same throughout the projection period, as the model assumes no change in age-specific HUI3 (for those with MS or with no neurological condition).

Although people with MS born in more recent decades can expect to live longer than those born in earlier decades, they will not live as long as those without MS. Women with MS born between 2010 and 2019 will live five fewer years than women without MS, while men with MS born in the same decade will live four fewer years than men without MS. People living with MS will experience longer periods of living in poor health relative to their counterparts who do not have MS (Table 2). For instance, females diagnosed with MS born between 2010 and 2019 are projected to lose an average of 19.8 years in full health compared to 12.4 years for their counterparts who do not have MS. Similarly, males with MS born in the same decade are projected to lose 17.2 years in full health compared to 10.7 years for those who have not been diagnosed with MS.

Table 3 provides a snapshot of the observed 2011 per capita health care costs for Canadians with MS and those without MS. At all ages, the mean total health care costs were substantially higher for those with MS than without MS. For instance, in the 20 to 24 age group, the projected total health care costs are about 13 times higher for those with MS than for those without MS. The health care costs attributed to living with MS remain consistently 5- to 10 -fold higher from ages 25 to 64 years, then drop to four times higher and remain stable for the rest of the age categories. When health care costs are subdivided, physician, hospital and prescription drug costs are consistently higher in the MS population than in the non-MS population (Table 3). However, the disparity between populations is greatest for drug costs, which are over 40 -fold higher in the MS population aged 20 to 24 years than in the non-MS population. 
FIGURE 5

Average Health Utilities Index Mark 3 score, population with multiple sclerosis and those with no neurological condition, by age, both sexes, Canada

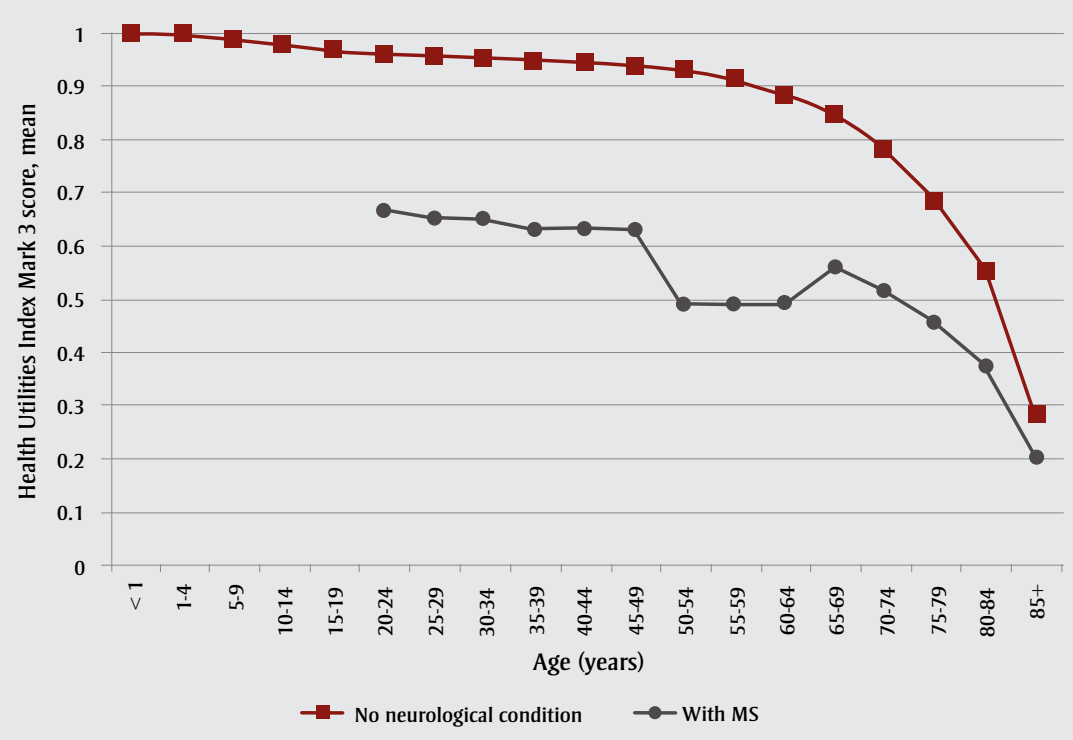

Sources: National Population Health Survey 1994-2010; 2011 Survey on Living with Neurological Conditions in Canada. Abbreviation: MS, multiple sclerosis.

The additional expenditures incurred by Canadians aged 20 years and older with MS are about three to eight times higher in the three main components (physician, hospital and drugs) than the expenditures incurred in the absence of seven major neurological conditions mentioned above. The additional costs incurred by those with MS are consistently higher among people aged 25 to 49 years but thereafter begin to

stabilize and then decrease (Table 4). By age 70 years, the gap between the base and additional expenditures decreases to threefold and remains at that level for the age groups 70 years and above, likely reflecting accrual of morbidity in the general population.

The total projected health care sector costs show that the additional expenditures due

TABLE 2

POHEM-Neurological mean years lived and health-adjusted life years, individuals with and without multiple sclerosis, by sex and decade of birth, Canada, 1970-2019

\begin{tabular}{|ccccc}
$\begin{array}{c}\text { Decade } \\
\text { of birth }\end{array}$ & $\begin{array}{c}\text { Individuals } \\
\text { with MS (YL) }\end{array}$ & $\begin{array}{c}\text { Individuals } \\
\text { without MS (YL) }\end{array}$ & $\begin{array}{c}\text { HALY for individuals } \\
\text { with MS }\end{array}$ & $\begin{array}{c}\text { HALY for individuals } \\
\text { without MS }\end{array}$ \\
\hline Female & & & & \\
\hline $1970-1979$ & 81.7 & 86.0 & 62.7 & 74.0 \\
$1980-1989$ & 82.5 & 86.9 & 63.0 & 74.7 \\
$1990-1999$ & 82.7 & 87.4 & 63.1 & 75.0 \\
$2000-2009$ & 82.9 & 87.6 & 63.2 & 75.2 \\
\hline $2010-2019$ & 83.0 & 87.7 & 63.2 & 75.3 \\
\hline Male & & & & 71.3 \\
\hline $1970-1979$ & 80.6 & 81.5 & 63.8 & 72.3 \\
\hline $1980-1989$ & 81.0 & 82.8 & 63.8 & 72.8 \\
\hline $1990-1999$ & 81.6 & 83.4 & 64.3 & 73.1 \\
\hline $2000-2009$ & 81.4 & 83.8 & 63.9 & 73.3 \\
\hline $2010-2019$ & 81.3 & 84.0 & 64.1 & \\
\hline
\end{tabular}

Abbreviations: HALY, health-adjusted life years; MS, multiple sclerosis; POHEM, Population Health Model; YL, years lived. to MS are about four times higher than the base expenditures associated with the condition. As well, these costs are projected to increase over the projection period. Additional expenditures incurred for drugs for the population with MS are about 10 to 20 times higher than for Canadians living without any of the seven major neurological conditions noted earlier. The trend is prominent between the ages of 20 and 49 years and persists throughout the 20-year projection period.

The total out-of-pocket expenses incurred by Canadians with MS are projected to increase from $\$ 126$ million in 2011 to $\$ 170$ million in 2031 (Table 5). Out-of-pocket costs start to rise around age 25 until age 54 years, when the costs begin to stabilize, and then begin to decrease after age 65 years; the decrease in the per capita cost may be partly due to mortality. The average out-of-pocket expenditure for people with MS is around $\$ 1300$ annually throughout the projection period.

The utilization of informal caregiving also reflects an additional burden on family and others associated with people living with MS. Based on 2011 data the proportion of Canadians receiving informal care is higher among those with MS than those with no neurological conditions across all age groups. It is estimated that $34 \%$ of those aged 20 to 24 years with MS have an informal caregiver, rising to $59 \%$ for those with MS aged 60 to 64 years (see Figure 6). In general, the burden for informal caregiving on people with MS emerges earlier and remains high throughout their lifetime.

\section{Discussion}

We used the POHEM-Neurological microsimulation model with status quo assumptions to project the changing nature of MS in Canada with respect to the incidence of new cases, rising prevalence and future burden, in terms of costs and impact on health over the next 20 years. By 2031, the prevalence of MS will exceed 400 persons per 100000 , corresponding to more than 133000 affected Canadians, and a 13\% change from 2011. After accounting for additional expenditures due to MS, total health sector costs for MS are expected to reach $\$ 2$ billion by 2031. Further, $65 \%$ of people living with MS are projected to need informal care by 2031 .

We found that people living with MS have a reduced life expectancy, and have longer 
TABLE 3

Estimated mean per capita costs for population with MS compared to those without MS, by major cost components and age group, Canada, 2011

\begin{tabular}{|c|c|c|c|c|c|c|c|c|c|c|c|c|}
\hline \multirow{2}{*}{$\begin{array}{l}\text { Age } \\
\text { group }\end{array}$} & \multicolumn{4}{|c|}{ With MS (\$) } & \multicolumn{4}{|c|}{ Without MS (\$) } & \multicolumn{4}{|c|}{ Ratio of MS to non-MS cost by age group } \\
\hline & $\begin{array}{l}\text { Health } \\
\text { care } \\
\text { sector }^{\mathrm{a}}\end{array}$ & Physician & Hospital & $\begin{array}{l}\text { Prescrip- } \\
\text { tion drugs }\end{array}$ & $\begin{array}{l}\text { Health } \\
\text { care } \\
\text { sector }^{\mathrm{a}}\end{array}$ & Physician & Hospital & $\begin{array}{l}\text { Prescrip- } \\
\text { tion } \\
\text { drugs }\end{array}$ & $\begin{array}{l}\text { Health } \\
\text { care } \\
\text { sector }^{\mathrm{a}}\end{array}$ & Physician & Hospital & $\begin{array}{l}\text { Prescrip- } \\
\text { tion drugs }\end{array}$ \\
\hline $20-24$ & 11158 & 1718 & 1480 & 7439 & 854 & 326 & 340 & 170 & $13: 1$ & $5: 1$ & $4: 1$ & $44: 1$ \\
\hline $25-29$ & 10845 & 1351 & 1249 & 7488 & 1066 & 411 & 420 & 216 & $10: 1$ & $3: 1$ & $3: 1$ & $35: 1$ \\
\hline $30-34$ & 10816 & 1275 & 2010 & 6760 & 1215 & 469 & 456 & 266 & 9:1 & $3: 1$ & $4: 1$ & $25: 1$ \\
\hline $35-39$ & 11011 & 1126 & 1928 & 6764 & 1216 & 457 & 414 & 315 & $9: 1$ & $2: 1$ & $5: 1$ & 21:1 \\
\hline $40-44$ & 12104 & 1217 & 2780 & 6145 & 1305 & 472 & 422 & 372 & 9:1 & $3: 1$ & $7: 1$ & $17: 1$ \\
\hline $45-49$ & 13375 & 1314 & 3247 & 5654 & 1575 & 538 & 513 & 468 & $8: 1$ & $2: 1$ & $6: 1$ & $12: 1$ \\
\hline $50-54$ & 14067 & 1313 & 3816 & 4927 & 1998 & 644 & 676 & 592 & $7: 1$ & $2: 1$ & $6: 1$ & $8: 1$ \\
\hline $55-59$ & 15947 & 1436 & 5111 & 4024 & 2514 & 754 & 882 & 750 & $6: 1$ & $2: 1$ & $6: 1$ & $5: 1$ \\
\hline $60-64$ & 16550 & 1532 & 4973 & 3543 & 3205 & 898 & 1201 & 917 & $5: 1$ & $2: 1$ & $4: 1$ & $4: 1$ \\
\hline $65-69$ & 18523 & 1607 & 6146 & 2542 & 4130 & 1096 & 1634 & 1123 & $4: 1$ & $1: 1$ & $4: 1$ & $2: 1$ \\
\hline $70-74$ & 22218 & 1906 & 6032 & 2447 & 5169 & 1278 & 2115 & 1350 & $4: 1$ & $1: 1$ & $3: 1$ & $2: 1$ \\
\hline $75-79$ & 27131 & 1964 & 8721 & 2433 & 6344 & 1444 & 2686 & 1521 & $4: 1$ & 1:1 & $3: 1$ & $2: 1$ \\
\hline $80-84$ & 30833 & 2153 & 7705 & 2666 & 7547 & 1502 & 3238 & 1603 & $4: 1$ & 1:1 & $2: 1$ & $2: 1$ \\
\hline $85+$ & 32310 & 2079 & 6906 & 2042 & 9196 & 1354 & 3711 & 1417 & $4: 1$ & $2: 1$ & $2: 1$ & 1:1 \\
\hline
\end{tabular}

Abbreviation: MS, multiple sclerosis.

${ }^{\text {a }}$ Total health care sector costs, including physician, hospital, drugs, rehabilitation, long-term care, home care and assistive devices.

periods of living with a poorer healthrelated quality of life (as reflected by lower scores on the HUI3), which limits their ability to participate in activities of daily living. Other studies have also shown that the MS population has lower quality of life than the general population. ${ }^{38}$ The HUI3 is strongly associated with physician-scored measures of disability, ${ }^{39}$ which tend to worsen with older age, ${ }^{40}$ consistent with our findings. Temporal trends in these associations have not been evaluated; thus, an assumption of stability in these trends across time was reasonable. As MS typically presents in young adults between the ages of 18 and 40 years, early disability and premature death mean that affected individuals have a reduced potential to contribute to economic activities.

Consistent with the existing literature, model outputs indicate that per capita health care expenditures are higher for individuals with $\mathrm{MS}^{41}$ than those in the non-MS population. Although the rate of hospitalization has declined in the MS population over time, rates remain higher than in an age- and sex-matched population without MS. ${ }^{42}$ Other health care services are also used more heavily by the MS population than the general population. ${ }^{38}$ Prescription drug expenditures are particularly high, likely reflecting the very high costs of disease-modifying therapies for MS. ${ }^{43}$ We observed that among those aged 20 to 34 years, the group most likely to be using disease-modifying therapies, prescription drug expenditures constituted $62.5 \%$ to $69 \%$ of total health care expenditures. In a survey of 1909 Americans with MS in 2006, disease-modifying therapies constituted the single biggest MSrelated cost, ${ }^{44}$ and in a US-based study that used administrative data, pharmacy expenditures constituted $65 \%$ of total MS-related health care costs in $2004 .{ }^{45}$

Although the microsimulation model projected only a slight increase in the prevalence of MS over the next 20 years, the burden of MS on affected individuals, the health system and society is projected to increase substantially. This increase reflects the improving life expectancy for people MS, with long periods lived in poor health and with functional disability. Formal health care costs will increase, and persons with MS will incur substantial out-ofpocket costs, which are expected to increase over the 20-year horizon. The demand for informal caregiving will also increase, further affecting the health and economic well-being of informal caregivers. ${ }^{46-48}$

\section{Strengths and limitations}

Our study projections fill gaps in current pan-Canadian population-based estimates, and are also consistent with the existing Canadian literature.

POHEM-Neurological used status quo assumptions related to incidence, relative mortality and functional health. With the exception of risks associated with age and sex, Canada's population growth, migration patterns and aging patterns are assumed to remain the same over the 
TABLE 4

POHEM-Neurological projected total health care costs ${ }^{\mathrm{a}}$ for individuals with $\mathrm{MS}$, divided into base and additional components to total expenditure, by age group and projection year, Canada

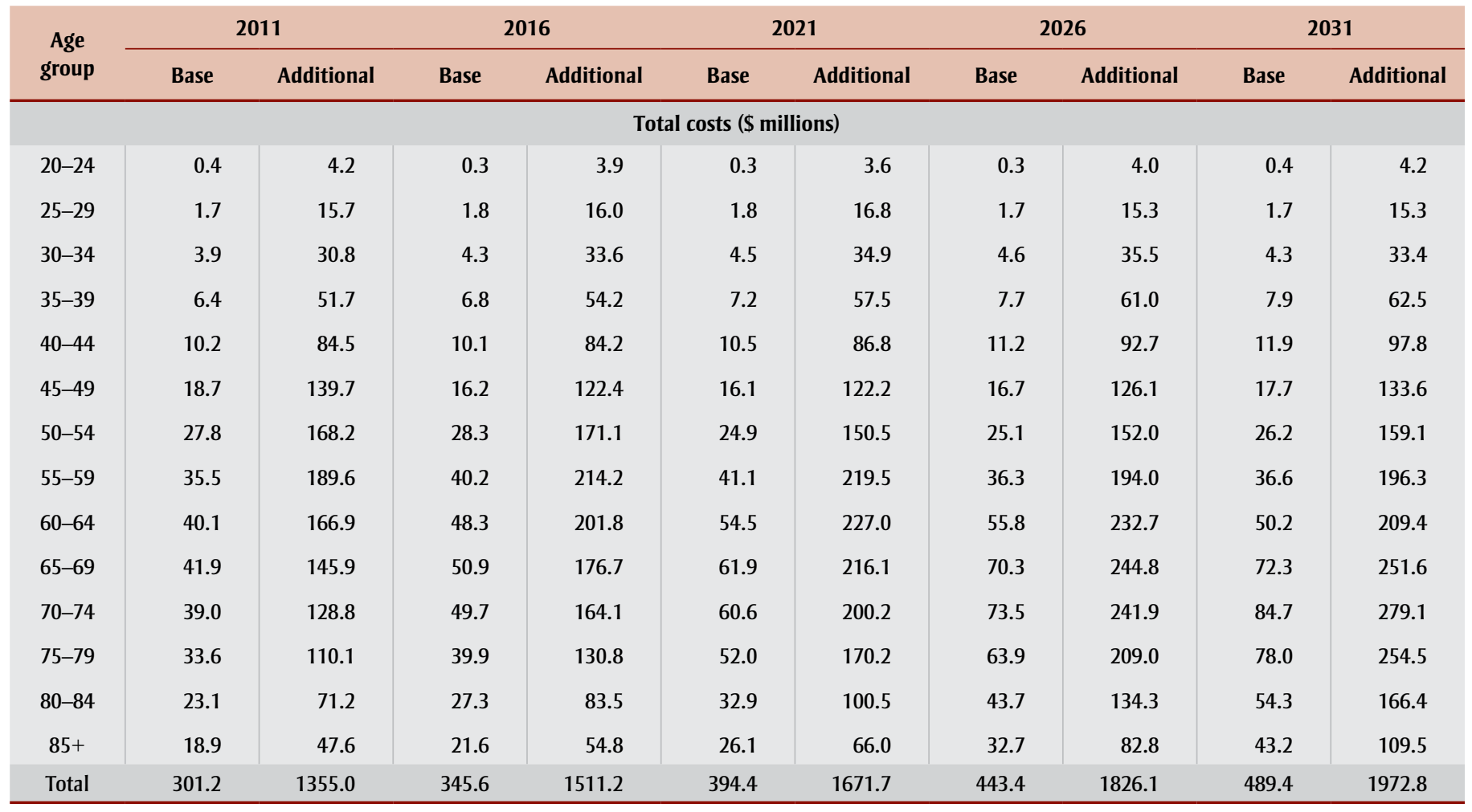

Abbreviations: MS, multiple sclerosis; POHEM, Population Health Model.

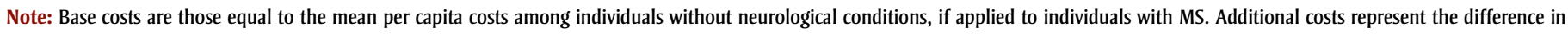
costs for individuals with MS compared to base costs.

${ }^{\text {a }}$ Total health care sector costs include physician, hospital, drugs, rehabilitation, long-term care, home care and assistive devices.

20-year projection time horizon. Other risk factors were not considered because it was unclear which risk factors were most salient, and because they were likely to vary over the projection period. The future trend in terms of a cure for MS is assumed to remain unchanged over the projection period, although advances in health care could provide alternative ways to prevent, diagnose or treat MS. POHEM-Neurological presumes that incident cases of MS begin to occur at age 20 , but up to $5 \%$ of individuals have symptom onset under age 16 years, ${ }^{49}$ although some of these individuals will not be diagnosed until adulthood. The effects of this assumption are likely to be small, given that most MS cases are diagnosed at age 20 years and older. The model shows peak incidence occurring at a later age than other Canadian studies undertaken in Nova Scotia ${ }^{21}$ and Manitoba;22 however, the overall incidence rates produced by the model were similar to these earlier studies.
Other limitations should be considered. The model projected a conservative increase in the prevalence of MS of $6.5 \%$ per decade. In all Canadian provinces where it has been evaluated over time, the prevalence of MS has increased, ${ }^{21-24,36}$ consistent with our findings. However, the degree of change has varied, from $13.5 \%$ per decade in Manitoba $^{22}$ to $55 \%$ per decade in Ontario. ${ }^{24}$ That variance could be a reflection of the application of diagnostic or reporting criteria, or, our findings may underestimate the future impact of MS.

Our findings also assume that there will be no major treatment advances that can improve function or reduce mortality, and that the general patterns of health services utilization will persist in the future (i.e. status quo assumptions). Future iterations of the POHEM-Neurological could address the limitations posed by such assumptions by incorporating additional primary research on risk- and prognosis-factor dynamics in MS.
Microsimulation itself has certain limitations, including susceptibility to the quality of data used as input parameters, and the ability to model and quantify uncertainty of projections. ${ }^{50}$ With respect to input data quality, while attempts are made to ensure that the most appropriate data are used in the model, newer data that are more accurate will become available in the future. Such information can be updated in a microsimulation model in the future, and the impact of such changes can be assessed. Regarding the projection uncertainty, methodologies intended to improve projection accuracy are currently under development that could be applied in future scenario projections. ${ }^{51,52}$

\section{Conclusion}

POHEM-Neurological has shed light on the escalating costs of MS and its social, economic and health impacts. People living with MS face progressive physical and cognitive impairment and reduced quality of life. A key policy issue is the cost of MS 
TABLE 5

Projected total out-of-pocket costs ${ }^{\mathrm{a}}$ for individuals with multiple sclerosis, by age group and projection year, Canada, 2011-2031

\begin{tabular}{|c|c|c|c|c|c|}
\hline \multirow{2}{*}{ Age group } & 2011 & 2016 & 2021 & 2026 & 2031 \\
\hline & \multicolumn{5}{|c|}{ Total costs ( $\$$ millions) } \\
\hline $20-24$ & 0.5 & 0.4 & 0.4 & 0.5 & 0.5 \\
\hline $25-29$ & 1.8 & 1.9 & 2.0 & 1.7 & 1.8 \\
\hline $30-34$ & 3.6 & 4.0 & 4.1 & 4.3 & 3.9 \\
\hline $35-39$ & 6.7 & 7.1 & 7.5 & 7.9 & 8.2 \\
\hline $40-44$ & 9.9 & 10.0 & 10.2 & 11.0 & 11.5 \\
\hline $45-49$ & 15.1 & 13.1 & 13.1 & 13.5 & 14.3 \\
\hline $50-54$ & 17.8 & 18.1 & 15.9 & 16.1 & 16.8 \\
\hline $55-59$ & 17.9 & 20.5 & 20.8 & 18.4 & 18.7 \\
\hline $60-64$ & 16.0 & 19.2 & 21.7 & 22.3 & 20.0 \\
\hline $65-69$ & 13.1 & 15.8 & 19.2 & 21.8 & 22.3 \\
\hline $70-74$ & 9.6 & 12.3 & 15.1 & 18.2 & 20.9 \\
\hline $75-79$ & 6.8 & 8.1 & 10.4 & 12.8 & 15.7 \\
\hline $80-84$ & 4.0 & 4.7 & 5.7 & 7.5 & 9.3 \\
\hline $85+$ & 2.8 & 3.2 & 3.8 & 4.8 & 6.4 \\
\hline Total & 125.7 & 138.2 & 149.9 & 160.7 & 170.4 \\
\hline
\end{tabular}

a Out-of-pocket expenses include costs incurred by a patient that are not reimbursed by provincial health plans.

and how best to mitigate the cost to society, as health care costs are projected to persistently increase, particularly for prescription drugs. Future microsimulation studies can be tailored to provide the

FIGURE 6

POHEM-Neurological projected proportion of individuals with an informal caregiver, individuals with MS and those without a neurological condition, by age group, Canada, 2011

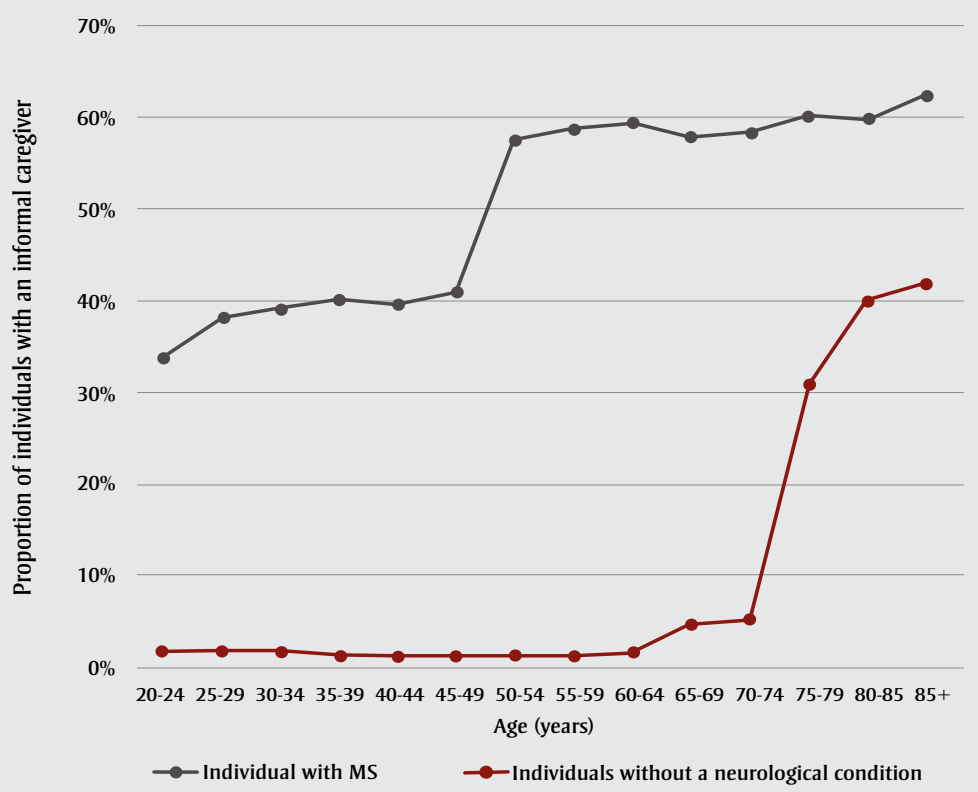

Source: POHEM-Neurological.

Abbreviations: MS, multiple sclerosis; POHEM, Population Health Model. recommendations aimed at reducing the societal impacts of the condition.

\section{Acknowledgements}

This study was supported by the Institute for Clinical Evaluative Sciences (ICES), which is funded by an annual grant from the Ontario Ministry of Health and LongTerm Care (MOHLTC). The opinions, results and conclusions reported in this paper are those of the authors and are independent from the funding sources. No endorsement by ICES or the Ontario MOHLTC is intended or should be inferred.

Parts of this material are based on data and information compiled and provided by CIHI. However, the analyses, conclusions, opinions and statements expressed herein are those of the authors, and not necessarily those of CIHI.

Dr. Karen Tu is a research scholar in the Department of Family and Community Medicine at the University of Toronto.

\section{Conflicts of interest}

The authors disclose no conflict of interest.

\section{Authors' contributions}

NA, RM, CB and RG contributed to the paper concept, drafting, analysis interpretation and critical review of the article. RM provided specialised content expertise on MS, while CB, RG, DGM, RW, PF, JB, $\mathrm{KT}$ and KR contributed to data acquisition, microsimulation modelling and review of the article.

\section{References}

1. Ploughman M, Beaulieu S, Harris C, et al. The Canadian survey of health, lifestyle and ageing with multiple sclerosis: methodology and initial results. BMJ Open. 2014;7(4):e005718. Erratum in: BMJ Open. 2015;5(3):e005718.

2. Evans C, Beland S-G, Kulaga S, et al. Incidence and prevalence of multiple sclerosis in the Americas: a systematic review. Neuroepidemiology. 2013; 40(3):195-210.

3. Pugliatti M, Rosati G, Carton H, et al. The epidemiology of multiple sclerosis in Europe. Eur J Neurol. 2006; 13(7):700-22. 
4. Rejdak K, Jackson S, Giovannoni G. Multiple sclerosis: a practical overview for clinicians. Br Med Bull. 2010; 95:79-104.

5. Karampampa K, Gustavsson A, Miltenburger C, et al. Treatment experience, burden, and unmet needs (TRIBUNE) in multiple sclerosis: the costs and utilities of MS patients in Canada. J Popul Ther Clin Pharmacol. 2012;19(1):e11-e25.

6. Berg-Hansen P, Celius EG. Socioeconomic factors and immigrant population studies of multiple sclerosis. Acta Neurol Scand. 2015; 132(Suppl. 199):37-41.

7. Wade BJ. Spatial analysis of global prevalence of multiple sclerosis suggests need for an updated prevalence scale. Mult Scler Int [Internet]. 2014 Feb 16 [cited 2015 Sept 30]; 2014: 124578. Available from: https://www .hindawi.com/journals/msi/2014 /124578/

8. Multiple Sclerosis International Federation. Atlas of MS 2013: mapping multiple sclerosis around the world. London: Multiple Sclerosis International Federation; 2013.

9. Neurological Health Charities Canada, Public Health Agency of Canada. Mapping connections: an understanding of neurological conditions in Canada. Ottawa (ON): Government of Canada; 2014 [Catalogue No.: HP35-45/2014E-PDF].

10. Simmons RD, Tribe KL, McDonald EA. Living with multiple sclerosis: longitudinal changes in employment and the importance of symptom management. J Neurol. 2010;257(6):926-36.

11. Tinghög P, Björkenstam C, Carstensen $\mathrm{J}$, et al. Co-morbidities increase the risk of disability pension among MS patients: a population-based nationwide cohort study. BMC Neurol. 2014; 14:117.

12. Sundström P, Nyström L, Svenningsson A, Forsgren L. Sick leave and professional assistance for multiple sclerosis individuals in Västerbotten County, northern Sweden. Mult Scler. 2003; 9(5):515-20.
13. MS Society of Canada. Action on MS (report) [Internet]. Toronto (ON): MS Society of Canada; 2014 [cited 2015 Sept 30]. Available from: http:// mslistening.ca/pdf/Action-on-MS -English-Online.pdf

14. Finès $\mathrm{P}$, Garner R, Bancej $\mathrm{C}$, Bernier $\mathrm{J}$, Manuel DG. Development and implementation of microsimulation models of neurological conditions. Health Rep. 2016;27(3):3-9.

15. Caesar-Chavannes CR, MacDonald S. National Population Health Study of Neurological Conditions in Canada. Chronic Dis Inj Can. 2013;33(3): 188-91.

16. Wolfson MC. POHEM-a framework for understanding and modelling the health of human populations. World Health Stat Q. 1994;47(3-4):157-76.

17. Santana MJ, Feeny DH. Using the health utilities index in routine clinical care: process, feasibility, and acceptability: a randomized controlled trial. Patient. 2009;2(3):159-67.

18. Manuel DG, Tuna M, Hennessy D, et al. Projections of preventable risks for cardiovascular disease in Canada to 2021: a microsimulation modelling approach. CMAJ Open. 2014;2(2): E94-E101.

19. Evans WK, Wolfson MC, Flanagan WM, et al. Canadian cancer risk management model: evaluation of cancer control. Int $\mathrm{J}$ Technol Assess Health Care. 2013;29(2):131-9.

20. Statistics Canada. Population projections for Canada, provinces and territories: 2009 to 2036. Ottawa (ON): Statistics Canada; 2010 [Statistics Canada, Catalogue No.: 91-520-X].

21. Marrie RA, Fisk JD, Stadnyk KJ, et al. The incidence and prevalence of multiple sclerosis in Nova Scotia, Canada. Can J Neurol Sci. 2013;40(6):824-31.

22. Marrie RA, Yu N, Blanchard J, Leung $\mathrm{S}$, Elliott $\mathrm{L}$. The rising prevalence and changing age distribution of multiple sclerosis in Manitoba. Neurology. 2010; 74(6):465-71.

23. Banwell B, Kennedy J, Sadovnick D, et al. Incidence of acquired demyelination of the CNS in Canadian children. Neurology. 2009;72(3):232-9.
24. Widdifield J, Ivers NM, Young J, et al. Development and validation of an administrative data algorithm to estimate the disease burden and epidemiology of multiple sclerosis in Ontario, Canada. Mult Scler. 2015; $21(8): 1045-54$.

25. Kingwell E, Zhu F, Marrie RA, et al. High incidence and increasing prevalence of multiple sclerosis in British Columbia, Canada: findings from over two decades (1991-2010). J Neurol. 2015;262(10):2352-63.

26. Mitchell D, Brockett P, MendozaArriaga R, et al. Modeling and forecasting mortality rates. Insur Math Econ. 2013;52(2):275-85.

27. Kingwell E, van der Kop M, Zhao Y, et al. Relative mortality and survival in multiple sclerosis: findings from British Columbia, Canada. J Neurol Neurosurg Psychiatry. 2012;83(1):61-6.

28. Fiest KM, Fisk JD, Patten SB, et al. Comorbidity is associated with pain-related activity limitations in multiple sclerosis. Mult Scler Relat Disord. 2015;4(5):470-6.

29. Jones CA, Pohar SL, Warren S, Turpin KV, Warren KG. The burden of multiple sclerosis: a community health survey. Health Qual Life Outcomes. 2008; $6: 1-7$.

30. Statistics Canada. Survey on Living with Neurological Conditions in Canada (SLNCC) 2011 [Internet]. Ottawa (ON): Statistics Canada; 2011. Available from: http://www23.statcan .gc.ca/imdb/p2SV.pl? Function $=$ getSurvey\&SDDS $=5182$

31. Statistics Canada. National Population Health Survey (NPHS) 2011 [Internet]. Ottawa (ON): Statistics Canada; 2011 [modified 2016 Mar 10]. Available from: http://www.statcan.gc.ca/eng /survey/household/3225

32. Statistics Canada. General Social Survey - caregiving and care receiving (GSS) 2012 [Internet]. Ottawa (ON): Statistics Canada; 2012 [modified 2013 Jul 9]. Available from: http://www23 .statcan.gc.ca/imdb/p2SV.pl?Function $=$ getSurvey $\&$ SDDS $=4502$

33. Marrie RA, Cohen J, Stuve O, et al. A systematic review of the incidence and prevalence of comorbidity in multiple sclerosis: overview. Mult Scler. 2015; 21(3):263-81. 
34. Marrie RA, Elliott L, Marriott J et al. Effect of comorbidity on mortality in multiple sclerosis. Neurology. 2015; 85(3):240-7.

35. Warren SA, Svenson LW, Warren KG. Contribution of incidence to increasing prevalence of multiple sclerosis in Alberta, Canada. Mult Scler. 2008; 14(7):872-9.

36. Statistics Canada. CANSIM database: Table 105-1300: Neurological conditions, by age group and sex, household population aged 0 and over, 2010/2011, occasional (number unless otherwise noted) [Internet]. Ottawa (ON): Statistics Canada; [modified 2012 Sep 17; cited 2016 Jan 15]. Available from: http://www5.statcan.gc.ca/cansim /a26?lang $=$ eng\&id $=1051300$

37. Finlayson M. Health and social profile of older adults with MS: findings from three studies. Int J Mult Scler Care. 2002;4(3):139-51.

38. Pohar SL, Jones CA, Warren S, Turpin KV, Warren K. Health status and health care utilization of multiple sclerosis in Canada. Can J Neurol Sci. 2007;34(2):167-74.

39. Fisk JD, Brown MG, Sketris IS, Metz LM, Murray TJ, Stadnyk KJ. A comparison of health utility measures for the evaluation of multiple sclerosis treatments. J Neurol Neurosurg Psychiatry. 2005;76(1):58-63.

40. Confavreux C, Vukusic S. Age at disability milestones in multiple sclerosis. Brain. 2006;129(Pt 3):595-605.

41. Campbell JD, Ghushchyan V, Brett McQueen R, et al. Burden of multiple sclerosis on direct, indirect costs and quality of life: national US estimates. Mult Scler Relat Disord. 2014;3(2): 227-36.

42. Marrie RA, Elliott L, Marriott J, et al. Dramatically changing rates and reasons for hospitalization in multiple sclerosis. Neurology. 2014;83(10): 929-37.

43. Hartung DM, Bourdette DN, Ahmed $\mathrm{SM}$, Whitham RH. The cost of multiple sclerosis drugs in the US and the pharmaceutical industry: too big to fail? Neurology. 2015;84(21):2185-92.
44. Kobelt G, Berg J, Atherly D, Hadjimichael O. Costs and quality of life in multiple sclerosis: a crosssectional study in the United States. Neurology. 2006;66(11):1696-1702.

45. Prescott JD, Factor S, Pill M, Levi GW. Descriptive analysis of the direct medical costs of multiple sclerosis in 2004 using administrative claims in a large nationwide database. J Manag Care Pharm. 2007;13(1):44-52.

46. Mitchell LA, Hirdes J, Poss JW, SlegersBoyd C, Caldarelli H, Martin L. Informal caregivers of clients with neurological conditions: profiles, patterns and risk factors for distress from a home care prevalence study. BMC Health Services Res. 2015;15:350.

47. Buchanan RJ, Huang C, Zheng Z. Factors affecting employment among informal caregivers assisting people with multiple sclerosis. Int J MS Care. 2013;15(4):203-10.

48. McKenzie T, Quig ME, Tyry T, et al. Care partners and multiple sclerosis. Differential effect on men and women. Int J MS Care. 2015;17(6):253-60.

49. Pena JA, Lotze TE. Pediatric multiple sclerosis: current concepts and consensus definitions. Autoimm Dis [Internet]. 2013 Sep 3 [cited 2015 Sept 30]; 2013: 673947. Available from: https://www .hindawi.com/journals/ad/2013 /673947

50. Hennessy DA, Flanagan WM, Tanuseputro P, et al. The Population Health Model (POHEM): an overview of rationale, methods and application. Popul Health Metrics. 2015;13:24. doi: 10.1186/s12963-015-0057-x.

51. Briggs AH, Weinstein MC, Fenwick EA, et al. Model parameter estimation and uncertainty analysis: a report of the ISPOR-SMDM modeling good research practices task force working group. Med Decision Making. 2012;32(5): 722-32.

52. Sharif B, Kopec JA, Wong $\mathrm{H}$, et al. Uncertainty analysis in populationbased microsimulation models. Epidemiol Res Int [Internet]. 2012 Jun 12 [cited 2015 Sept 30]; 2012:610405. Available from: https://www.hindawi. com/journals/eri/2012/610405/ 